\title{
Additive manufacturing of star poly(e-caprolactone) wet-spun scaffolds for bone tissue engineering applications
}

\author{
Carlos Mota ${ }^{1}$, Dario Puppi ${ }^{1}$, Dinuccio Dinucci ${ }^{1}$, Matteo Gazzarri ${ }^{1}$ and Federica Chiellini ${ }^{{ }^{*}}$ \\ ${ }^{1}$ Laboratory of Bioactive Polymeric Materials for Biomedical and Environmental Applications (BIOLab), Department of Chemistry \\ and Industrial Chemistry, University of Pisa, via Vecchia Livornese 1291, 56010 San Piero a Grado (Pi), Italy.
}

* Corresponding author: Federica Chiellini, Department of chemistry and Industrial chemistry, University of Pisa, Pisa (Italy). E-mail:federica@dcci.unipi.it, Tel:+39-050-2210305, Fax:+39-050-2210332

Keywords: tissue engineering, scaffolds, wet-spinning, rapid prototyping, additive manufacturing, star polymers, polycaprolactone.

\begin{abstract}
Three-dimensional fibrous scaffolds made of a three-arm star poly( $\varepsilon$-caprolactone) (*PCL) were developed by employing a novel computer-aided wet-spinning apparatus to precisely control the deposition pattern of an extruded polymeric solution as a filament into a coagulation bath. *PCL and *PCL/hydroxyapatite (HA) composite scaffolds composed by fibres with a porous morphology both in the outer surface and in the cross-section were successfully produced with a layer-by-layer approach achieving good reproducibility of the internal architecture and external shape. Changes in processing parameters allowed fabricating scaffolds with different architectural parameters in terms of average pore size in the XY axes (from 190 to $297 \mu \mathrm{m}$ ) and in the $\mathrm{Z}$ axis (from 54 to $126 \mu \mathrm{m}$ ), and porosity (in the range $20 \%$ to $60 \%$ ). Mechanical characterization showed that processing conditions variation and HA loading influenced scaffold compressive properties. Cell culture experiments carried out by using a murine preosteoblast cell line showed good cell response in terms of proliferation and osteoblastic differentiation. The obtained results suggest the suitability of the proposed technique for the production of customized polymeric scaffolds for bone tissue engineering applications.
\end{abstract}

\section{INTRODUCTION}

The most common approach in the field of tissue engineering (TE) involves the employment of a three-dimensional (3D) matrix of synthetic or natural origin (commonly referred to as scaffold), often combined with cells and/or bioactive agents, that serves as a temporary platform for tissue regeneration at the affected site until the normal physiological functions are restored ${ }^{1,2}$. A scaffold should be biocompatible, biodegradable (ideally, the degradation 
rate should match the rate of formation of the new tissue) and should support cell activity while the new extracellular matrix $(E C M)$ is formed ${ }^{3}$. In addition, a complex scaffold structure with proper porosity, pore size, pore distribution and external shape is a key requirement for a successful regeneration process ${ }^{4}$.

In order to process materials with different physical-chemical and processing properties as scaffolds with a porous architecture, several fabrication techniques (e.g. freeze drying, solvent casting combined with particulate leaching, phase inversion techniques, fibre bonding and electrospinning) have been investigated in the last two decades ${ }^{5}$. However, most of them present major drawbacks, including poor control over pore size, distribution and interconnection as well as external scaffold shape and size ${ }^{6}$. Additive manufacturing (AM) techniques, also called solid freeform fabrication techniques, represent a promising alternative due to the possibility of producing scaffolds with tailored morphology and mechanical properties. Different AM techniques based on layer upon layer fabrication of scaffolds from 3D model data, such as: fused deposition modeling, stereolithography, selective laser sintering and 3D printing $^{7}$, have been investigated in the past years for the development of complex 3D structures for TE applications. Wet-spinning is a non-solvent induced phase inversion technique, based on an immersion-precipitation process, originally developed for the production of continuous polymeric fibres for diverse industrial applications ${ }^{8}$. Thanks to the possibility of processing a wide range of natural and synthetic polymers, different fabrication procedures based on wet-spinning fibre production were recently proposed for the preparation of TE scaffolds. Indeed, a number of studies published over the last years have shown the possibility to produce scaffolds composed by wet-spun fibres made of chitosan ${ }^{9,10}$, starch-based materials ${ }^{11-15}$ and three-arm star poly( $\varepsilon$-caprolactone) $(* \text { PCL })^{16,17}$, through either a physical bonding of prefabricated fibres or a continuous, randomly-oriented deposition of the solidifying wet-spun filament in the coagulation bath. Although the obtained microfibrous scaffolds possessed an interconnected porous structure generally providing good in vitro cell adhesion and proliferation with penetration of cells into the inner part of the scaffold, the proposed techniques suffer from lack of control over pore architecture as well as over scaffold external shape, which is limited to simple geometries. Moreover, they require a dedicated operator to perform the whole fibre collection process by a manual motion of the collection system and/or to carry out the post-processing fibre bonding step. In order to overcome these limitations, an AM technique based on wet-spinning of polymeric solutions was recently applied for the layer-by-layer fabrication of 3D poly( $\varepsilon$-caprolactone) (PCL) scaffolds achieving good control over internal architecture and external shape as well as good degree of automation ${ }^{18}$.

Star polymers consist of linear polymer chains attached to a small central moiety. Due to their small size, spherical structure and limited interaction between molecules, they have different properties compared to the linear polymers with equivalent molecular weight, such as lower crystallinity as well as lower melting and solution viscosity, resulting in different processing and degradation properties ${ }^{19-22}$. ${ }^{*}$ PCL, consisting of three linear PCL chains with approximately the same molecular weight attached to a central aluminium core ${ }^{23,24}$, was recently used to form electrospun and wetspun non-woven TE meshes that showed promising results when tested in cell culture experiments using preosteoblast cells ${ }^{17,25}$.

Hydroxyapatite (HA), a synthetic osteoconductive ceramic with a chemical composition resembling that of bone apatite, has been extensively studied for bone TE applications often in combination with polymeric materials to enhance its toughness ${ }^{26,27}$. In addition, the incorporation of HA particles into polymer matrices has been shown to improve the osteoconductivity and mechanical properties of polymeric scaffolds and to create a $\mathrm{pH}$ buffer against the acidic degradation products of biodegradable polyesters ${ }^{28-30}$.

The aim of the present study was to develop 3D *PCL and *PCL/HA composite wet-spun scaffolds with predefined internal microstructure and external shape by employing the computer-aided wet-spinning technique previously 
employed for the layered manufacturing of PCL scaffolds ${ }^{18}$. A novel wet-spinning apparatus allowing enhanced computer-control over fabrication parameters was developed by modifying a commercial rapid prototyping system. The influence of different processing parameters, i.e. polymer concentration $\left(\mathrm{C}_{* \mathrm{PCL}}\right)$, deposition velocity $\left(\mathrm{V}_{\mathrm{dep}}\right)$ and solution feed rate (F), on scaffold architecture and porosity was evaluated by means of scanning electron microscopy (SEM). Moreover, the developed scaffolds were characterized for their compressive mechanical behaviour by uniaxial static test, thermal properties by thermogravimetric analysis (TGA) and differential scanning calorimetry (DSC) and in vitro cytocompatibility by using the MC3T3-E1 murine preosteoblast cell line.

\section{MATERIALS AND METHODS}

\section{Materials}

Three-arm star branched poly( $\varepsilon$-caprolactone) ( $\left.{ }^{*} \mathrm{PCL}, \mathrm{Mw}=189,000 \mathrm{~g} / \mathrm{mol}\right)$, was provided by Michigan Biotechnology Institute (Lansing, MI, USA), hydroxyapatite nanoparticles (HA, size $<200 \mathrm{~nm}$ ) were bought from Sigma-Aldrich (Milan, Italy). Acetone and ethanol were purchased from Sigma-Aldrich (Milan, Italy) and used as received.

THROUGH OUT THE EXPEIMENTAL ONLY,

PLEASE CHANGE ALL "hours and minutes" TO "h" and "min” RESPECTIVELY

\section{Computer-aided wet-spinning apparatus}

Scaffolds were produced using an in-house modified subtractive Rapid Prototyping system (MDX-40A, ROLAND DG Mid Europe Srl, Ancona, Italy). The milling head unit was replaced with a syringe pump system (NE-1000, New Era Pump Systems Inc., Wantagh, NY, USA) to enable the deposition of polymeric solutions with a controlled 3D pattern (Figure 1a). The lay-down pattern for scaffold production was calculated using an algorithm developed in Matlab software (The Mathworks, Inc.) and uploaded into the equipment through the software Vpanel for MDX-40A.

\section{Solutions preparation}

*PCL pellets were dissolved in acetone at $35^{\circ} \mathrm{C}$ for $3 \mathrm{~h}$ under gentle stirring to obtain homogeneous solutions at the desired concentrations (15 to $30 \% \mathrm{w} / \mathrm{v}$ ). For the production of *PCL/HA composite scaffolds, HA nanoparticles were added to the polymeric solution and left under vigorous stirring at $35^{\circ} \mathrm{C}$ for $1 \mathrm{~h}$ until a homogeneous dispersion of the nanoparticles was achieved. On the basis of the results achieved in a previous study ${ }^{17}$, the weight ratio between HA and *PCL in the solution was chosen to be $25 \%$.

\section{Scaffold production and design}

The prepared solution was loaded into a $5 \mathrm{ml}$ syringe, fitted with a blunt tip stainless steel needle (inner diameter $=0.34$ $\mathrm{mm}$, length $=15 \mathrm{~mm}$ ), and placed into the syringe pump. The 3D scaffolds with predefined architectures were fabricated with a layer-by-layer process, using the previously described computer-aided wet-spinning apparatus, by extruding the solution directly into a glass beaker containing ethanol (Figure 1a). The initial distance between the tip of the needle and the bottom of the beaker $\left(Z_{0}\right)$ was $1 \mathrm{~mm}$. A deposition trajectory aimed at the production of scaffolds with $0-90^{\circ}$ lay-down pattern, distance between fibre axis $\left(\mathrm{d}_{2}\right)$ of $500 \mu \mathrm{m}$ and layer thickness $\left(\mathrm{d}_{3}\right)$ of $200 \mu \mathrm{m}$ was employed (Figure $1 \mathrm{~b}$ ). The effect of different processing parameters such as $\mathrm{V}_{\mathrm{dep}} \mathrm{C}_{* \mathrm{PCL}}$ and $\mathrm{F}$ on fibre collection and 
morphology was evaluated (Table 1). Samples of cylindrical geometry with a diameter of around $15 \mathrm{~mm}$ and composed of 25 layers for mechanical characterization or 10 layers for biological investigations were produced. After fabrication, the scaffolds were removed from the coagulation bath and kept under a fume hood overnight. Residual solvents were removed by keeping the scaffolds in a vacuum chamber for $48 \mathrm{~h}$.

\section{Morphological analysis}

The scaffold morphology was assessed using scanning electron microscopy (SEM, JEOL LSM 5600LV, Tokio, Japan) under backscattered electron imaging. SEM micrographs were acquired from the top view and the cross-section (obtained by fracture in liquid nitrogen) of the scaffolds at different magnifications. Structural parameters, such as average fibre diameter $\left(\mathrm{d}_{1}\right)$ and pore size, were determined by means of ImageJ $1.43 \mathrm{u}$ software (National Institutes of Health, Bethesda, MD, USA) on SEM micrographs with a 35X magnification. Data were calculated over 20 measurements per scaffold.

The scaffold porosity was evaluated using the theoretical approach proposed by Landers et $a l^{31}$ :

$$
P=\left(1-\frac{\text { Vscaffold }}{\text { Vcube }}\right) \times 100=\left(1-\frac{\pi}{4} \cdot \frac{d_{1}^{2}}{d_{2} d_{3}}\right) \times 100
$$

where $P$ is the porosity of the scaffold, $d_{1}$ is the fibre diameter, $d_{2}$ the distance between fibre axis and $d_{3}$ layer thickness. The microporosity of the single fibre was not considered in this calculation.

\section{Thermal properties}

Thermal properties of the raw materials and scaffolds were evaluated by means of thermogravimetric analysis (TGA) and differential scanning calorimetry (DSC). TGA was performed using a TGA Q500 instrument (TA Instruments, Milan, Italy) in the temperature range $30-600^{\circ} \mathrm{C}$, at a heating rate of $20^{\circ} \mathrm{C} \cdot \mathrm{min}^{-1}$ and under a nitrogen flow of 60 $\mathrm{mL} \cdot \mathrm{min}^{-1}$. The degradation temperature $\left(\mathrm{T}_{\mathrm{d}}\right)$ was evaluated as the temperature corresponding to a percentage weight loss of $5 \%$.

DSC analysis was performed in the range -100 to $100^{\circ} \mathrm{C}$, at a heating and cooling rate of $10^{\circ} \mathrm{C} \cdot \mathrm{min}^{-1}$ and under a nitrogen flow rate of $80 \mathrm{~mL} \cdot \mathrm{min}^{-1}$, using a Mettler DSC-822 (Mettler Toledo, Milan, Italy). By considering the first and second heating cycle in the thermograms, glass transition temperature $\left(\mathrm{T}_{\mathrm{g}}\right)$ was evaluated by analysing the inflection point, while melting temperature $\left(\mathrm{T}_{\mathrm{m}}\right)$ and crystallinity by analysing the endothermic peak.

\section{Mechanical characterization}

Compression characterization was performed at room temperature and ambient humidity using an INSTRON 5564 (Instron Corporation, MA, USA) equipped with a $2 \mathrm{kN}$ load cell. Five samples of each scaffold type with a diameter (d) of $13.2 \pm 0.5$ and height $\left(\mathrm{h}_{0}\right)$ of $3.9 \pm 0.2 \mathrm{~mm}$ were tested. The samples were compressed by employing two parallel plates at a strain rate of $0.5 \mathrm{~mm} \cdot \mathrm{min}^{-1}$ and up to a strain value of $0.5 \mathrm{~mm} \cdot \mathrm{mm}^{-1}$. The stress was defined as the measured force divided by the total area of the apparent cross-section of the scaffold, whilst the strain was evaluated as the ratio between the scaffold height variation and its initial height. 


\section{Biological evaluation}

\section{Scaffold sterilization}

Scaffolds were placed in a 24 -well plate, exposed to UV light for $2 \mathrm{~h}$ on each side and disinfected with $70 \%$ ethanol/water solution for $3 \mathrm{~h}$. After ethanol removal, scaffolds were extensively washed with Dulbecco's Phosphate Buffer Saline (DPBS, pH 7.4) containing $1 \%$ penicillin/streptomycin and were then left overnight at $37^{\circ} \mathrm{C}$ in $5 \% \mathrm{CO}_{2}$.

\section{Cell culturing and cell seeding}

Mouse calvaria-derived preosteoblastic cells (MC3T3-E1) subclone 4 were obtained from the American Type Culture Collection (ATCC CRL-2593) (LGC Standards, Milan, Italy) and cultured as monolayers in Alpha Minimum Essential Medium ( $\alpha$-MEM, Sigma-Aldrich, Milan, Italy), containing ribonucleosides, deoxyribonucleosides and sodium bicarbonate, supplemented with L-glutamine $(2 \mathrm{mM})$, fetal bovine serum (10\%), penicillin:streptomycin solution $(100 \mathrm{U} / \mathrm{ml}: 100 \mu \mathrm{g} / \mathrm{ml})(1 \%)$ and antimycotic agent (Invivogen, Milan, Italy). The cultures were mantained at $37{ }^{\circ} \mathrm{C}$ in $5 \% \mathrm{CO}_{2}$.

MC3T3 cells were seeded at an appropriate density $\left(0.5 \times 10^{4}\right)$ onto the scaffolds as previously described ${ }^{18}$. Twentyfour $\mathrm{h}$ after seeding, scaffolds were incubated with osteogenic medium by supplementing the $\alpha$-MEM with ascorbic acid $(0.3 \mathrm{mM})^{32}$ and $\beta$-glycerophosphate $(10 \mathrm{mM})^{33}$, in order to induce and promote the osteoblastic phenotype expression of MC3T3-E1. The medium was replaced every $48 \mathrm{~h}$.

\section{Cell viability and cell proliferation}

Cell viability and proliferation were measured by using the cell proliferation reagent WST-1 (Roche Diagnostics, Monza, Italy) on days 7, 14, 21 and 28, after cell seeding, as previously described ${ }^{18}$. Briefly, the assay was performed by incubating cell-seeded scaffolds with the reagent for $4 \mathrm{~h}$. Measurements of formazan dye absorbance were carried out at $450 \mathrm{~nm}$.

\section{Quantification of collagen production}

Assessment of collagen production by MC3T3-E1 cultured on *PCL based scaffolds, as an indicator of osteoblastic marker, was carried out at day 7 and 28. At each time point the medium was removed and the samples were washed twice with DPBS. Scaffolds were then incubated with Direct Red 80 dye (Sigma-Aldrich, Milan, Italy) dissolved in picric acid $(0.1 \%)$, for $1 \mathrm{~h}$ at room temperature. After incubation the dye solution was removed and the samples were washed three times with $10 \mathrm{mM} \mathrm{HCl}$ to remove the excess dye. The elution of the bound stain was performed with 0.1 $\mathrm{N} \mathrm{NaOH}$ for $30 \mathrm{~min}$ at $37^{\circ} \mathrm{C}$. Supernatants were plated in a 96 -well plate and the absorbance was read at $540 \mathrm{~nm}$. Scaffolds without cells were treated with the same protocol and considered as blank.

The photometric quantification of the collagen was obtained by means of a calibration curve prepared with collagen type I, derived from calf's skin (Sigma-Aldrich, Milan, Italy). Briefly, known concentrations of collagen in acetic acid $(0.1 \mathrm{M})$ were filmed and dried on glass slides by a solvent casting technique in order to obtain a thin film. Films were then fixed and treated as the samples ${ }^{34}$. 


\section{Alkaline phosphatase (ALP) activity}

Alkaline phosphatase (ALP) activity was determined in cultured MC3T3-E1-*PCL constructs on days 7, 14, 21, and 28, as previously described ${ }^{18}$. Briefly, scaffolds were washed three times with DPBS, treated with lysis buffer followed by freezing-thawing cycles. Subsequently the supernatant was taken from the samples, added into $p$-nitrophenyl phosphate substrate (Sigma-Aldrich, Milan, Italy) and the reaction was left to take place at $37^{\circ} \mathrm{C}$ for 30 min. The absorbance was measured at $405 \mathrm{~nm}$ using a spectrophotometer. The molar concentration of ALP was normalized with the total protein content of each sample, which was measured using the Bradford protein assay (Pierce, Rockford, IL, USA). The results for ALP activity assay were reported as nanomoles (nmol) of converted substrate per minute and mg of total proteins.

\section{Cell morphology investigation by confocal laser scanning microscopy (CLSM)}

The morphology of MC3T3-E1 cells grown on *PCL constructs and their 3D organization were investigated on day 7 , 14, 21, and 28 by means of a Nikon Eclipse TE2000 (Nikon Instruments, Florence, Italy) inverted microscope equipped with an EZ-C1 confocal laser setup. Cells were fixed with 3.8\% p-formaldehyde for 30 min and processed as previously described ${ }^{18}$. Captured images were further processed with The GIMP (GNU Free Software Foundation) image manipulation software and merged with Nikon ACT-2U software.

\section{Statistical evaluation}

Quantitative data were presented as mean \pm standard deviation (SD). Data sets were screened by one-way ANOVA and a Tukey test was used for post hoc analysis; significance was defined at $\mathrm{p}<0.05$.

\section{RESULTS AND DISCUSSION}

*PCL and *PCL/HA composite scaffolds were prepared by a new computer-aided wet-spinning apparatus that allows for enhanced control of the deposition process on the three XYZ axes (Figure 1c). The processing conditions for the obtainment of $3 \mathrm{D}$ structures with a controlled internal network of pores and a predesigned external shape were investigated. The developed scaffolds were characterized for their morphological, thermal and mechanical properties as well as for their cytocompatibility using the MC3T3-E1 murine preosteoblast cell line.

\section{Additive Manufacturing (AM) of scaffolds}

The AM process involved the extrusion of a polymeric solution directly into a coagulation bath and the synchronized motion of the needle and of the construction platform for the deposition of the solidifying solution filament with a predefined pattern. The solvent/non-solvent (acetone/ethanol) system optimized in previous work on *PCL wetspinning 16,17 was employed. Parameters, such as lay-down pattern, needle inner diameter, needle tip-to-beaker bottom initial distance $\left(Z_{0}\right), Z$ inter-layer needle translation distance $\left(d_{3}\right)$ and distance between XY deposition lines $\left(d_{2}\right)$, were chosen on the base of preliminary investigations and kept constant during the study of the influence of $\mathrm{C}_{* \mathrm{PCL}}, \mathrm{V}_{\mathrm{dep}}$ and $\mathrm{F}$ on scaffold morphology.

SEM image analysis showed good reproducibility of the internal architecture of the scaffolds in terms of fibre morphology and size, fibre alignment and layered structure. The scaffolds were composed of overlapping layers of oriented *PCL fibres. Individual fibres had a highly porous morphology both at the outer surface and in cross-section 
(Figures 2 and 3). The fibre porosity was a consequence of the solution filament solidification mechanism based on the solvent-non-solvent counter-diffusion in the coagulation bath. This induced a phase separation into a polymer-rich matrix surrounding polymer-lean droplets that formed the pores after complete solidification and solvent removal ${ }^{17}$.

The computer-aided wet-spinning technique offers all of the typical advantages of the melt-extrusion based AM technique (e.g. Fused Deposition Modelling )such as, customized pore size, pore geometry and 3D external shape ${ }^{18}$. In comparison to dense strands fabricated by FDM, the porous morphology of the single fibres constituting the wet-spun scaffolds can present some advantages in influencing the biodegradation rate, the mass transfer associated with drug release and cell metabolic activities that regulate cell adhesion and proliferation ${ }^{4,18}$. In addition, the process can accommodate loading the scaffolds with bioactive agents that are sensitive to high temperatures but have good stability in the solvents employed (i.e. acetone and ethanol). The major concerns of the technique are the need of a postprocessing step to eliminate residual organic solvents from the polymeric matrix, and the lower mechanical performance in comparison to that achieved by FDM due to the spongy morphology of the single fibre ${ }^{18}$. In addition, the relatively large pore size and fiber diameter of the obtained scaffolds (Table 1) will not allow all the advantages of nanofibrous electrospun assemblies, that greatly favour cell adhesion and provide a 3D microenvironment ideal for cellcell interaction ${ }^{35-41}$. Future studies will combine the 3D microstructure by computer-aided wet-spinning, conferring the anatomical shape and mechanical stability to the scaffold, and a nanosized fibrous structure by electrospinning which can enhance the biological performance of the scaffold ${ }^{42}$.

\section{Effect of polymer concentration $\left(C_{* P C L}\right)$}

The influence of $\mathrm{C}_{* \mathrm{PCL}}$ on scaffold morphology was investigated in the range of $15-30 \% \mathrm{w} / \mathrm{v}$ while keeping constant $\mathrm{V}_{\text {dep }}\left(240 \mathrm{~mm} \cdot \mathrm{min}^{-1}\right)$ and $\mathrm{F}\left(1 \mathrm{ml} \cdot \mathrm{h}^{-1}\right)$. When $\mathrm{C}_{* \mathrm{PCL}}$ was lower than $20 \% \mathrm{w} / \mathrm{v}$, the filament solidification process was too slow to obtain a fibrous structure and widespread fibre-fibre fusion was observed. An increase in $\mathrm{C}_{* \mathrm{PCL}}$ resulted in enhanced fibre morphology and thus in a well-defined 3D fibrous structure (Figure 2a). Analysing the top view SEM micrographs of fibre collections obtained for $\mathrm{C}_{* \mathrm{PCL}}$ from 20 to $30 \% \mathrm{w} / \mathrm{v}$, a more uniform fibre morphology and better fibre alignment was evident for scaffolds obtained at higher concentrations. In particular, fibres look flattened at the fibre-fibre intersection points for lower concentrations, and the bonding area in the conjunction region decreased with the increasing of $\mathrm{C}_{* \mathrm{PCL}}$. As shown in table 1 , this caused a statistically significant increase of pore size along $\mathrm{Z}$ axis by increasing $\mathrm{C}_{* \text { PCL }}$ leading to an increase of scaffold porosity. However, non-significant differences in $d_{1}$ and $d,\left(d_{2}\right.$ ?) and as consequence, in XY pores, were observed. In addition, as shown by high magnification micrographs (Figure 3), the increase in $\mathrm{C}_{* \mathrm{PCL}}$ led to a more porous morphology of fibre outer surface. The best results, in terms of fibre morphology and alignment as well as scaffold porosity, was achieved for $\mathrm{C}_{* \mathrm{PCL}}$ of $30 \% \mathrm{w} / \mathrm{v}$, making this concentration ideal for further processing parameters studies.

The morphology of porous structures obtained through phase inversion by non-solvent addition is strongly related to solvent/non-solvent demixing kinetics ${ }^{43}$. In the case of slow demixing, a uniform pore structure, in terms of size, geometry and distribution, is usually achieved. Inversely, a fast demixing originates a dense "skin" on the surface interfacing with the coagulant fluid and an irregular pore distribution underneath, typically presenting finger-like pores. A number of papers suggested that when polymer concentration is increased a slower solvent/non-solvent mixing takes place ${ }^{44-47}$. The results achieved in the present study are consistent with those of previous research suggesting that an increase of polymer concentration in a certain range leads to a more uniform wet-spun fibre porosity likely because of a slower demixing ${ }^{48}$. In addition, the diminished effect of fibre flattening at the contact points with increasing $\mathrm{C}_{* \mathrm{PCL}}$ can be also explained with the slower demixing and/or the increased solution viscosity. 


\section{Effect of deposition velocity $\left(V_{\text {dep }}\right)$ and solution feed rate $(F)$}

The effect of $\mathrm{V}_{\mathrm{dep}}$ on scaffold morphology was evaluated in the range 180 to $300 \mathrm{~mm} \cdot \mathrm{min}^{-1}$ at the optimized $\mathrm{C}_{* \mathrm{PCL}}(30 \%$ $\mathrm{w} / \mathrm{v})$ and constant $\mathrm{F}\left(1 \mathrm{ml} \cdot \mathrm{h}^{-1}\right)$. When $\mathrm{V}_{\text {dep }}$ was below $200 \mathrm{~mm} \cdot \mathrm{min}^{-1}$ the formation of a porous structure was compromized due to fibre-fibre fusion within the same layer, while in the case of $V_{\text {dep }}$ above $280 \mathrm{~mm} \cdot \mathrm{min}^{-1}$ the adhesion between adjacent layers was limited, compromising the structural integrity of the scaffold. However, when $\mathrm{V}_{\text {dep }}$ was in the range 200 to $280 \mathrm{~mm} \cdot \mathrm{min}^{-1}$ a $3 \mathrm{D}$ fully interconnected porous structure, characterized by a good degree of fibre alignment, was obtained (Figure $2 b$ ). By increasing $V_{\text {dep }}$ in this range, $d_{1}$ decreased significantly and, accordingly, XY pores size and scaffold porosity increased (table 1). However, scaffolds obtained at the high $\mathrm{V}_{\text {dep }}$ showed in some cases delamination between adjacent layers, likely because of the limited merging at the fibre-fibre contact points. The influence of $F$ was investigated in the range 0.6 to $1.2 \mathrm{ml} \cdot \mathrm{h}^{-1}$ keeping constant the optimized conditions of $\mathrm{C}_{* \mathrm{PCL}}$ and $\mathrm{V}_{\text {dep }}\left(30 \% \mathrm{w} / \mathrm{v}\right.$ and $240 \mathrm{~mm} \cdot \mathrm{min}^{-1}$, respectively). Delamination of the layered structure was observed for low values of $\mathrm{F}$, while fibre-fibre fusion was too marked compromising scaffold porosity along $\mathrm{Z}$ axis when $1.2 \mathrm{ml} \cdot \mathrm{h}^{-1}$ was applied. However, when $\mathrm{F}$ was in the range $0.8-1.1 \mathrm{ml} \cdot \mathrm{h}^{-1}$, good fibre morphology and alignment were achieved (Figure 2c). By increasing $\mathrm{F}$ in this range, fibres looked more flattened at the contact points, and $\mathrm{d}_{1}$ increased significantly while scaffold porosity decreased (table 1). Considering the results obtained from the above presented investigations, the optimized processing conditions for $*$ PCL scaffold fabrication were $\mathrm{C}_{* \mathrm{PCL}}=30 \% \mathrm{w} / \mathrm{v}, \mathrm{V}_{\mathrm{dep}}$ $=240 \mathrm{~mm} \cdot \mathrm{min}^{-1}$ and $\mathrm{F}=1.0 \mathrm{ml} \cdot \mathrm{h}^{-1}$.

A proper balance between $\mathrm{F}$ and $\mathrm{V}_{\text {dep }}$ is necessary for the deposition of a straight fibre with cylindrical morphology, which is needed for its uniform stretching. This balance is needed as well for partial fusion at the fibre-fibre contact points, which is essential for a cohesive 3D architecture with good integrity and mechanical behaviour. As shown in the current study, by varying either $\mathrm{V}_{\mathrm{dep}}$ or $\mathrm{F}$ in a certain range it is possible to optimize fibre morphology and to tune fibre diameter, pore size and overall scaffold porosity. However, if $\mathrm{V}_{\mathrm{dep}}$ is too high or $\mathrm{F}$ too low, the stretching force acting on the solidifying filament can cause its breaking or can limit fibre-fibre contact area where interlayer adhesion takes place. In addition, for a given distance between the needle tip and the previous layer (depending on $Z_{0}$ and $d_{3}$ ), inappropriate $\mathrm{V}_{\mathrm{dep}} / \mathrm{F}$ combinations can result in a low velocity of the solution filament that solidifies before settling onto the previously deposited layer, thus limiting the adhesion at the fibre-fibre contact points. On the contrary, if $\mathrm{V}_{\mathrm{dep}}$ is too low or $\mathrm{F}$ too high, the filament is not solidified enough when it reaches the previous layer and a controlled fibrous deposition is compromized due to non-uniform fibre morphology or excessive fibre-fibre fusion.

\section{Effect of hydroxyapatite (HA) loading}

By applying the optimized $\mathrm{V}_{\text {dep }}$ and $\mathrm{F}\left(240 \mathrm{~mm} \cdot \mathrm{min}^{-1}\right.$ and $1 \mathrm{ml} \cdot \mathrm{h}^{-1}$, respectively), HA-loaded *PCL scaffolds (HA/*PCL weight ratio of $25 \%$ ) were fabricated by processing solutions with different $\mathrm{C}_{* \mathrm{PCL}}(20$ or $30 \% \mathrm{w} / \mathrm{v})$. Composite scaffolds revealed a morphology close to that of plain *PCL scaffolds with good degree of fibre alignment (Figure 4a,b). For the HA-loaded *PCL scaffold, a change of $\mathrm{C}_{* \mathrm{PCL}}$ had a significant effect on the obtained $\mathrm{d}_{1}$ but not on the pore size in $\mathrm{XY}$ and $\mathrm{Z}$ axis (Table 1). Moreover, $\mathrm{d}_{1}$ was significantly smaller while the $\mathrm{XY}$ and $\mathrm{Z}$ pore sizes were significantly larger when compared to plain *PCL scaffolds. High magnification SEM micrographs showed a good dispersion of HA nanoparticle microaggregates both in the outer surface and in the cross-section of the fibres (Figure 4c,d). According to a previous study on wet-spun $* \mathrm{PCL}^{17}$, the surface and cross-section porosity of HA-loaded scaffolds was lower in 
comparison to plain *PCL scaffolds obtained by applying the same processing conditions (Figure 4c,d vs Figure 3c,f). The presence of additives in the polymer solution can indeed affect the kinetics and thermodynamics of the phaseinversion process and therefore the resulting fibre morphology ${ }^{17,49-52}$. The lower porosity observed may be due to a faster solidification and an interaction between $* \mathrm{PCL}$ and $\mathrm{HA}$ in the solution, which affects polymer solvation and consequently the coagulation process ${ }^{17}$. Analogously, the lower fibre size of HA-loaded scaffolds may be related to such an effect on solidification kinetics.

\section{Mechanical Characterization}

The compressive mechanical properties of the developed scaffolds were evaluated by means of a uniaxial testing machine (strain rate $=0.5 \mathrm{~mm} \cdot \mathrm{min}^{-1}$ and maximum strain $=0.5 \mathrm{~mm} \cdot \mathrm{mm}^{-1}$ ) and the effect of $\mathrm{C}_{*_{\mathrm{PCL}}}$ in the range $20-30 \%$ $\mathrm{w} / \mathrm{v}\left(\mathrm{V}_{\text {dep }}=240 \mathrm{~mm} \cdot \mathrm{min}^{-1}\right.$ and $\left.\mathrm{F}=1.0 \mathrm{ml} \cdot \mathrm{h}^{-1}\right)$ and HA loading on mechanical parameters was investigated. The stressstrain curves (Figure 5) showed an initial linear region followed by a plateau and a subsequent region of increasing slope. As discussed in previous articles investigating the mechanical behaviour of porous scaffold structures fabricated by melt extrusion-based AM techniques ${ }^{53,54}$, the linear region is likely due to the response of the fibre-fibre contact points to the applied deformation, the subsequent plateau region to the collapse of the pores network and the final increase of the compressive stress to a further densification of the scaffold structure.

As reported in Table 2, an increase of $\mathrm{C}^{*} \mathrm{PCL}$ in the investigated range led to a significant increase of compressive modulus from $1.42 \pm 0.44$ to $3.62 \pm 0.94 \mathrm{MPa}$ and maximum stress from $0.54 \pm 0.08$ to $0.96 \pm 0.11 \mathrm{MPa}$. This can be explained by the more uniform fibre morphology at the contact points when higher $\mathrm{C}_{* \mathrm{PCL}}$ was employed. In addition, the HA-loaded scaffolds showed a significantly higher compressive modulus and strength in comparison with the *PCL plain scaffolds, corroborating results from previous studies investigating the effect of HA-loading on mechanical properties of scaffolds fabricated by melt extrusion-based ${ }^{55-60}$ or solution extrusion-based techniques ${ }^{18}$.

In comparison with linear PCL scaffolds fabricated using the same AM technique ${ }^{18}$, the developed *PCL scaffolds showed significantly higher mechanical properties, that may be explained by the different macromolecular structure of the two polymers, the higher polymer concentration employed in this study and/or the more advanced technological solutions that provide a better deposition resolution. However, the manufactured scaffolds still present mechanical properties insufficient for application in load-bearing bone tissues. Further studies should be conducted to investigate the enhancement of scaffold mechanical properties by increasing HA loading and/or by increasing fibre packing density together with decreasing fibre diameter.

\section{Thermal properties}

The thermal properties of optimized *PCL-based scaffolds, obtained employing the processing parameters $\left(\mathrm{C}_{* \mathrm{PCL}}=30 \%\right.$ $\mathrm{w} / \mathrm{v}, \mathrm{V}_{\text {dep }}=240 \mathrm{~mm} \cdot \mathrm{min}^{-1}$ and $\mathrm{F}=1.0 \mathrm{ml} \cdot \mathrm{h}^{-1}$ ) that achieved the best performance in terms of morphology and mechanical properties, were investigated in comparison to unprocessed *PCL (Table 3). As shown by TGA characterization, the degradation temperature $\left(\mathrm{T}_{\mathrm{d}}\right)$ of scaffolds and unprocessed polymer was above $300^{\circ} \mathrm{C}$. The amount of HA actually loaded in the composite scaffolds was estimated by the analysis of the residue weight percentage at $550^{\circ} \mathrm{C}$ that was $22.92 \%$, nearly the HA weight percentage in the polymeric solution $(20 \% \mathrm{wt})$. DSC analysis was performed in order to study the effect of materials processing and HA loading on *PCL thermal properties. By comparing data from the first scan, fibrous-structured *PCL showed higher crystallinity and lower $\mathrm{T}_{\mathrm{m}}$ than raw *PCL, while $T_{g}$ values were comparable. However, second scan analysis (after sample melting to remove previous thermal 
history) showed that the thermal properties of processed *PCL were comparable to those of raw *PCL, suggesting that wet-spinning didn't cause remarkable chemical-physical changes in polymer structure.

Crystallinity influences different properties of biodegradable polyesters such as degradation rate. Indeed, since water molecules and enzymes diffuse first into amorphous domains, polymer degradation rate is directly correlated to its crystallinity degree that changes during hydrolytic degradation ${ }^{61,62}$. As shown in previous studies, the solidification process and conditions involved in different techniques for the preparation of PCL-based constructs (e.g. compression moulding, solvent casting, phase inversion techniques) greatly influence polymer crystallinity ${ }^{61,63}$. The comparative DSC analysis of the current study corroborates results of other research activities finding that phase inversion-based material processing can significantly affect the crystallization process during polymer solidification and that a slow, gradual precipitation from solution generally allows the development of high levels of crystallinity ${ }^{61,64,65}$. Changes in coagulation kinetics induced by acting on different phase inversion conditions (e.g. solvent/non-solvent system, polymer concentration, coagulation time and temperature, presence of additives) can thus represent an effective tool for varying the crystallinity, and as consequence degradation rate and mechanical properties, of wet-spun fibrous scaffolds made of biodegradable polyesters.

\section{Biological evaluation}

\section{Cell viability and proliferation on scaffolds}

Biological investigations of the prepared *PCL scaffolds were carried out in order to evaluate cell viability and proliferation using the MC3T3-E1 cell line. Quantitative evaluation of cell proliferation onto scaffolds was performed weekly by means of the WST-1 assay. Results highlighted the ability of all investigated samples to sustain cell proliferation in both growing conditions (Figure 6a). At the very beginning the cell-material interactions and the cell seeding density played a crucial role on cell attachment and influenced the cell proliferation in the early culturing times $^{66}$. In fact, during the first two weeks of culture a delay in cell proliferation was observed for both culture conditions and scaffold types. This behaviour was especially evident for MC3T3-E1 cultured on *PCL/HA constructs. The HA presence in the construct could positively influence the switch between proliferation and differentiation

process $^{32}$, by promoting the expression of cell osteoblastic phenotype with a decrease in cell proliferation. ${ }^{25}$. Values of cell viability and proliferation were also compared to those observed for wet-spun linear PCL constructs ${ }^{18}$, which confirmed the good cytocompatibility as well as the slight delay in MC3T3-E1 cell proliferation when cells were grown in the presence of synthetic HA in the polymeric matrix.

\section{Collagen production}

Collagen production of preosteoblast cells, cultured on *PCL and *PCL/HA scaffolds, was measured and quantified as reported in Figure $6 \mathrm{~b}$. The 3D constructs induced MC3T3-E1 cells to produce high levels of collagen in agreement with previous studies using *PCL electrospun meshes ${ }^{25}$. Both types of scaffold and culturing conditions showed statistically significant values $(p<0.001)$ of collagen production with a sharply increasing time-dependent trend, confirming the bioactivity and the suitability of the prepared supports as bone substitutes.

\section{ALP activity measurement}


ALP is considered an early indicator of osteoblastic phenotype expression and its activity was measured to determine the MC3T3-E1 preosteoblast cell differentiation ${ }^{67}$.

In the first three weeks of culture, MC3T3-E1 grown on *PCL and *PCL/HA scaffolds produced comparable ALP levels with no visible increase during the culturing period (Figure. 6c). Significant levels of ALP were present during the first week $(\mathrm{p}<0.05)$.

A considerable increase in ALP levels was observed for the samples treated with osteogenic medium. This phenomenon confirmed that ascorbic acid and $\beta$-glycerophosphate support phenotypic differentiation by triggering the enzyme's expression $^{33,68}$. The presence of a synthetic calcium phosphate ceramic (i.e. HA), selected as a reinforcing bioactive agent in the *PCL constructs, did not improve the scaffolds' osteoconductivity during the first 21 days of culture. Increasing values of ALP were detected at the endpoint of analysis (day 28) for all the investigated samples. In particular, the osteogenic medium and the synergy between the modified medium and the HA polymeric matrix that mimics the natural apatite composition of bones and teeth, seemed to induce MC3T3-E1 cell differentiation. This result is confirmed by data from the literature ${ }^{69,70}$. Moreover, this behaviour confirmed the need for the MC3T3-E1 to reach an adequate cell confluence on the 3D constructs combined with the production of early matrix proteins as type I collagen, fibronectin and transforming growth factor beta (TGF- $\beta 1$ ), prior to the expression of high levels of ALP, an early marker of mature osteoblast function ${ }^{32,70,71}$.

\section{Cell culture organization on scaffolds}

Fluorescent staining of F-actin and nuclei of cells showed preosteoblast colonization of the cultured scaffolds. At early stages of culture (day 7), microscopic observation showed a poor presence of adherent cells on fibre surfaces in every experimental condition, confirming the cell proliferation data. Moreover, cells displayed a variable shape and spreading consistent with early stages of cell adaptation to the material ${ }^{60}$ (Figure 7). At days 14 and 21, the lower cell number of MC3T3-E1 grown on *PCL/HA constructs compared to those present on plain *PCL based scaffolds was rather evident. In accordance with the in vitro differentiation model ${ }^{32,70}$, after an initial phase characterized by replication of undifferentiated cells, preosteoblasts started the differentiation process ceasing proliferation. At the final culture endpoint (day 28), MC3T3-E1 cultures in differentiating conditions exhibited polygonal morphology with a cytoskeleton structure resembling the osteoblast phenotype (Figure 8). Plain *PCL samples, lacking any differentiating stimulus, exhibited the higher level of cell viability.

All scaffolds allowed preosteoblasts growth and colonization, revealing similar results at early stages but suggesting, at longer culture times, suitability for differentiation toward osteoblast phenotype under appropriated differentiation conditions.

\section{CONCLUSIONS}

An improved computer-assisted apparatus for wet-spinning of polymeric solutions with enhanced control over fabrication parameters was employed to produce highly porous 3D *PCL or *PCL/HA-based composite scaffolds. The fabrication process showed good reproducibility of the internal architecture and external shape as well as low production time. The scaffolds were composed of aligned fibres with a highly porous morphology, due to the phase inversion process governing solution filament solidification. A proper tuning of $\mathrm{C}_{* \mathrm{PCL}}, \mathrm{F}$ and $\mathrm{V}_{\text {dep }}$ enabled variation of fibre diameter, pore size and scaffold porosity. A change in $\mathrm{C}_{* \mathrm{PCL}}$ and HA-loading enhanced the compressive mechanical properties. The *PCL and *PCL/HA scaffolds were fully cytocompatible and able to sustain murine 
preosteoblast MC3T3-E1 cell adhesion, proliferation and colonization. Moreover, osteogenic markers confirmed the suitability of the prepared scaffolds to promote the osteoblastic differentiation process. The in vivo evaluation of these types of *PCL scaffolds on New Zealand rabbits is part of an ongoing research that will be published in a forthcoming paper.

\section{ACKNOWLEDGMENTS}

This work was done partly within the framework of the European Network of Excellence "EXPERTISSUES" (Project NMP3-CT-2004-500283) and partly in the framework of Hyanji Scaffold project PIRSES-GA-2008-230791. Mr. Piero Narducci and Mrs. Aura Bonaretti of University of Pisa, Italy, are acknowledged for recording SEM images.

\section{REFERENCES}

1. Stock U.A., Vacanti J.P. (2001). Tissue engineering: current state and prospects. Annual review of medicine. 52:443-451.

2. Hutmacher D.W., Cool S. (2007). Concepts of scaffold-based tissue engineering - the rationale to use solid free-form fabrication techniques. Journal of cellular and molecular medicine. 11(4):654-669.

3. Kim B.-S., Mooney D.J. (1998). Development of biocompatible synthetic extracellular matrices for tissue engineering. Trends in Biotechnology. 16(5):224-230.

4. Karageorgiou V., Kaplan D. (2005). Porosity of 3D biomaterial scaffolds and osteogenesis. Biomaterials. 26(27):5474-5491.

5. Puppi D., Chiellini F., Piras A.M., Chiellini E. (2010). Polymeric materials for bone and cartilage repair. Progress in Polymer Science. 35(4):403-440.

6. Sachlos E., Czernuszka J.T. (2003). Making tissue engineering scaffolds work. Review: the application of solid freeform fabrication technology to the production of tissue engineering scaffolds. European cells \& materials. 5:29-40.

7. Mota C., Puppi D., Chiellini F., Chiellini E. (2012). Additive manufacturing techniques for the production of tissue engineering constructs. Journal of Tissue Engineering and Regenerative Medicine.

8. Tuzlakoglu K., Reis R.L. (2008). Chitosan-based scaffolds in orthopaedic applications, Natural-based Polymers for Biomedical Applications, Reis R.L.357-373, Woodhead, Cambridge.

9. Heinemann C., Heinemann S., Lode A., Bernhardt A., Worch H., Hanke T. (2009). In vitro evaluation of textile chitosan scaffolds for tissue engineering using human bone marrow stromal cells. Biomacromolecules. 10(5):1305-1310.

10. Yilgor P., Tuzlakoglu K., Reis R.L., Hasirci N., Hasirci V. (2009). Incorporation of a sequential BMP-2/BMP7 delivery system into chitosan-based scaffolds for bone tissue engineering. Biomaterials. 30(21):3551-3559.

11. Leonor I.B., Rodrigues M.T., Gomes M.E., Reis R.L. (2011). In situ functionalization of wet-spun fibre meshes for bone tissue engineering. Journal of Tissue Engineering and Regenerative Medicine. 5(2):104-111.

12. Tuzlakoglu K., Pashkuleva I., Rodrigues M.T., Gomes M.E., van Lenthe G.H., Muller R., et al. (2010). A new route to produce starch-based fiber mesh scaffolds by wet spinning and subsequent surface modification as a way to improve cell attachment and proliferation. Journal of biomedical materials research Part A. 92(1):369-377.

13. Pashkuleva I., López-Pérez P.M., Azevedo H.S., Reis R.L. (2010). Highly porous and interconnected starchbased scaffolds: Production, characterization and surface modification. Materials Science and Engineering: C. 30(7):981-989.

14. Gomes M.E., Sikavitsas V.I., Behravesh E., Reis R.L., Mikos A.G. (2003). Effect of flow perfusion on the osteogenic differentiation of bone marrow stromal cells cultured on starch-based three-dimensional scaffolds. Journal of Biomedical Materials Research Part A. 67A(1):87-95.

15. Gomes M.E., Bossano C.M., Johnston C.M., Reis R.L., Mikos A.G. (2006). In vitro localization of bone growth factors in constructs of biodegradable scaffolds seeded with marrow stromal cells and cultured in a flow perfusion bioreactor. Tissue Eng. 12(1):177-188. 
16. Puppi D., Dinucci D., Bartoli C., Mota C., Migone C., Dini F., et al. (2011). Development of 3D wet-spun polymeric scaffolds loaded with antimicrobial agents for bone engineering. Journal of Bioactive and Compatible Polymers. 26(5):478-492.

17. Puppi D., Piras A.M., Chiellini F., Chiellini E., Martins A., Leonor I.B., et al. (2011). Optimized electro- and wet-spinning techniques for the production of polymeric fibrous scaffolds loaded with bisphosphonate and hydroxyapatite. Journal of Tissue Engineering and Regenerative Medicine. 5(4):253-263.

18. Puppi D., Mota C., Gazzarri M., Dinucci D., Gloria A., Myrzabekova M., et al. (2012). Additive manufacturing of wet-spun polymeric scaffolds for bone tissue engineering. Biomedical microdevices. 14(6):11151127.

19. McKee M.G., Unal S., Wilkes G.L., Long T.E. (2005). Branched polyesters: recent advances in synthesis and performance. Progress in Polymer Science. 30(5):507-539.

20. Burchard W. (1999). Solution properties of branched macromolecules. Advances in Polymer Science. 143:113194.

21. McKee M.G., Wilkes G.L., Colby R.H., Long T.E. (2004). Correlations of solution rheology with electrospun fiber formation of linear and branched polyesters. Macromolecules. 37(5):1760-1767.

22. Celik A., Kemikli N., Ozturk R., Muftuoglu A.E., Yilmaz F. (2009). Synthesis, characterization and thermal properties of a novel star polymer consisting of poly([epsilon]-caprolactone) arms emanating from an octa-functional porphyrazine core. Reactive and Functional Polymers. 69(9):705-713.

23. Balakrishnan S., Krishnan M., Dubois P., Narayan R. (2004). Kinetic and thermodynamic considerations in the synthesis of a new three-arm poly(E-caprolactone). Polymer Engineering and Science. 44(8):1491-1497.

24. Balakrishnan S., Krishnan M., Narayan R., Dubois P. (2006). Three-arm poly (E-caprolactone) by extrusion polymerization. Polymer Engineering \& Science. 46(3):235-240.

25. Puppi D., Detta N., Piras A.M., Chiellini F., Clarke D.A., Reilly G.C., et al. (2010). Development of electrospun three-arm star poly( $\varepsilon$-caprolactone) meshes for tissue engineering applications. Macromolecular bioscience. 10(8):887-897.

26. Ma P.X. (2008). Biomimetic materials for tissue engineering. Advanced drug delivery reviews. 60(2):184-198.

27. Sopyan I., Mel M., Ramesh S., Khalid K.A. (2007). Porous hydroxyapatite for artificial bone applications. Science and Technology of Advanced Materials. 8(1-2):116-123.

28. Rezwan K., Chen Q.Z., Blaker J.J., Boccaccini A.R. (2006). Biodegradable and bioactive porous polymer/inorganic composite scaffolds for bone tissue engineering. Biomaterials. 27(18):3413-3431.

29. Ural E., Kesenci K., Fambri L., Migliaresi C., Piskin E. (2000). Poly(d,1-cactide/عcaprolactone)/hydroxyapatite composites. Biomaterials. 21(21):2147-2154.

30. Koh Y.-H., Bae C.-J., Sun J.-J., Jun I.-K., Kim H.-E. (2006). Macrochanneled poly (ع-caprolactone)/ hydroxyapatite scaffold by combination of bi-axial machining and lamination. Journal of Materials Science: Materials in Medicine. 17(9):773-778.

31. Landers R., Pfister A., Hübner U., John H., Schmelzeisen R., Mülhaupt R. (2002). Fabrication of soft tissue engineering scaffolds by means of rapid prototyping techniques. Journal of Materials Science. 37(15):3107-3116.

32. Quarles L.D., Yohay D.A., Lever L.W., Caton R., Wenstrup R.J. (1992). Distinct proliferative and differentiated stages of murine MC3T3-E1 cells in culture: An in vitro model of osteoblast development. Journal of Bone and Mineral Research. 7(6):683-692.

33. Wang J., Yu X. (2010). Preparation, characterization and in vitro analysis of novel structured nanofibrous scaffolds for bone tissue engineering. Acta Biomaterialia. 6(8):3004-3012.

34. Junquiera L.C., Junqueira L.C., Brentani R.R. (1979). A simple and sensitive method for the quantitative estimation of collagen. Anal Biochem. 94(1):96-99.

35. Puppi D., Piras A.M., Detta N., Ylikauppila H., Nikkola L., Ashammakhi N., et al. (2011). Poly(vinyl alcohol)based electrospun meshes as potential candidate scaffolds in regenerative medicine. Journal of Bioactive and Compatible Polymers. 26(1):20-34.

36. Volpato F., Ramos S.L., Motta A., Migliaresi C. (2011). Physical and in vitro biological evaluation of a PA 6/MWCNT electrospun composite for biomedical applications. Journal of Bioactive and Compatible Polymers. 26(1):35-47.

37. Guarino V., Alvarez-Perez M., Cirillo V., Ambrosio L. (2011). hMSC interaction with PCL and PCL/gelatin platforms: A comparative study on films and electrospun membranes. Journal of Bioactive and Compatible Polymers. 26(2):144-160.

38. Toncheva A., Spasova M., Paneva D., Manolova N., Rashkov I. (2011). Drug-loaded electrospun polylactide bundles. Journal of Bioactive and Compatible Polymers. 26(2):161-172. 
39. Bianco A., Bozzo B.M., Del Gaudio C., Cacciotti I., Armentano I., Dottori M., et al. (2011). Poly (L-lactic acid)/calcium-deficient nanohydroxyapatite electrospun mats for bone marrow stem cell cultures. Journal of Bioactive and Compatible Polymers. 26(3):225-241.

40. Hualin Z. (2011). Electrospun poly (lactic-co-glycolic acid)/ multiwalled carbon nanotubes composite scaffolds for guided bone tissue regeneration. Journal of Bioactive and Compatible Polymers. 26(4):347-362.

41. Piras A.M., Chiellini F., Chiellini E., Nikkola L., Ashammakhi N. (2008). New Multicomponent Bioerodible Electrospun Nanofibers for Dual-controlled Drug Release. Journal of Bioactive and Compatible Polymers. 23(5):423443.

42. Mota C., Puppi D., Dinucci D., Errico C., Bártolo P., Chiellini F. (2011). Dual-Scale Polymeric Constructs as Scaffolds for Tissue Engineering. Materials. 4(3):527-542.

43. Smolders C.A., Reuvers A.J., Boom R.M., Wienk I.M. (1992). Microstructures in phase-inversion membranes. Part 1. Formation of macrovoids. Journal of Membrane Science. 73(2-3):259-275.

44. Kim H.J., Tyagi R.K., Fouda A.E., Ionasson K. (1996). The kinetic study for asymmetric membrane formation via phase-inversion process. Journal of Applied Polymer Science. 62(4):621-629.

45. Hou C., Liang Y., Wang C.-G. (2005). Determination of the diffusion coefficient of H2O in polyacrylonitrile fiber formation. Journal of Polymer Research. 12(1):49-52.

46. Arbab S., Zeinolebadi A., Noorpanah P. (2011). Exploring the thermodynamic aspects of structure formation during wet-Spinning of polyacrylonitrile fibres. International Journal of Chemoinformatics and Chemical Engineering (IJCCE). 1(2):36-52.

47. Hou C., Qu R., Wang C., Ying L. (2006). Diffusion coefficient of DMF in acrylic fiber formation. Journal of Applied Polymer Science. 101(6):3616-3619.

48. Arbab S., Noorpanah P., Mohammadi N., Soleimani M. (2008). Designing index of void structure and tensile properties in wet-spun polyacrylonitrile (PAN) fiber. I. Effect of dope polymer or nonsolvent concentration. Journal of Applied Polymer Science. 109(6):3461-3469.

49. Kim J.H., Lee K.H. (1998). Effect of PEG additive on membrane formation by phase inversion. Journal of Membrane Science. 138(2):153-163.

50. Mulder M. (1996). Influence of various parameters on membrane morphology, Basic Principle of Membrane Technology, Mulder M. 2nd. ed.123-140, Kluwer Academic Dordrecht, The Netherlands.

51. Reuvers A.J., Smolders C.A. (1987). Formation of membranes by means of immersion precipitation : Part II. the mechanism of formation of membranes prepared from the system cellulose acetate-acetone-water. Journal of Membrane Science. 34(1):67-86.

52. Strathmann H., Kock K., Amar P., Baker R.W. (1975). The formation mechanism of asymmetric membranes. Desalination. 16(2):179-203.

53. Zein I., Hutmacher D.W., Tan K.C., Teoh S.H. (2002). Fused deposition modeling of novel scaffold architectures for tissue engineering applications. Biomaterials. 23(4):1169-1185.

54. Domingos M., Chiellini F., Gloria A., Ambrosio L., Bartolo P., Chiellini E. (2012). Effect of process parameters on the morphological and mechanical properties of 3D Bioextruded poly(?-caprolactone) scaffolds. Rapid Prototyping Journal. 18(1):56-67.

55. Shor L., Guceri S., Wen X., Gandhi M., Sun W. (2007). Fabrication of three-dimensional polycaprolactone/hydroxyapatite tissue scaffolds and osteoblast-scaffold interactions in vitro. Biomaterials. 28(35):5291-5297.

56. Kyriakidou K., Lucarini G., Zizzi A., Salvolini E., Mattioli Belmonte M., Mollica F., et al. (2008). Dynamic co-seeding of osteoblast and endothelial cells on 3D polycaprolactone scaffolds for enhanced bone tissue engineering. Journal of Bioactive and Compatible Polymers. 23(3):227-243.

57. Domingos M., Chiellini F., Gloria A., Ambrosio L., Bartolo P.J., Chiellini E. (2009). BioExtruder: Study of the influence of process parameters on PCL scaffolds properties, Innovative Developments in Design and Manufacturing Advanced Research in Virtual and Rapid Prototyping, Bartolo P.J.67-73, Taylor \& Francis, Oxford, UK.

58. Gloria A., Russo T., De Santis R., Ambrosio L. (2009). 3D fiber deposition technique to make multifunctional and tailor-made scaffolds for tissue engineering applications. 7(3):141-152.

59. Bartolo P., Domingos M., Gloria A., Ciurana J. (2011). BioCell Printing: Integrated automated assembly system for tissue engineering constructs. CIRP Annals - Manufacturing Technology. 60(1):271-274.

60. Hutmacher D.W., Schantz T., Zein I., Ng K.W., Teoh S.H., Tan K.C. (2001). Mechanical properties and cell cultural response of polycaprolactone scaffolds designed and fabricated via fused deposition modeling. Journal of Biomedical Materials Research. 55(2):203-216.

61. Coombes A.G.A., Rizzi S.C., Williamson M., Barralet J.E., Downes S., Wallace W.A. (2004). Precipitation casting of polycaprolactone for applications in tissue engineering and drug delivery. Biomaterials. 25(2):315-325. 
62. Zong X.-H., Wang Z.-G., Hsiao B.S., Chu B., Zhou J.J., Jamiolkowski D.D., et al. (1999). Structure and morphology changes in absorbable poly(glycolide) and poly(glycolide-co-lactide) during in vitro degradation. Macromolecules. 32(24):8107-8114.

63. Peña J., Corrales T., Izquierdo-Barba I., Doadrio A.L., Vallet-Regí M. (2006). Long term degradation of poly( $\varepsilon$-caprolactone) films in biologically related fluids. Polymer Degradation and Stability. 91(7):1424-1432.

64. Rissanen M., Puolakka A., Hukka T., Ellä V., Nousiainen P., Kellomäki M. (2009). Effect of process parameters on properties of wet-spun poly(L,D-lactide) copolymer multifilament fibers. Journal of Applied Polymer Science. 113(4):2683-2692.

65. Gao H., Gu Y., Ping Q. (2007). The implantable 5-fluorouracil-loaded poly(l-lactic acid) fibers prepared by wet-spinning from suspension. Journal of Controlled Release. 118(3):325-332.

66. Kommareddy K.P., Lange C., Rumpler M., Dunlop J.W.C., Manjubala I., Cui J., et al. (2010). Two stages in three-dimensional in vitro growth of tissue generated by osteoblastlike cells. Biointerphases. 5(2):45-52.

67. Beck G.R., Sullivan E.C., Moran E., Zerler B. (1998). Relationship between alkaline phosphatase levels, osteopontin expression, and mineralization in differentiating MC3T3-E1 osteoblasts. Journal of Cellular Biochemistry. 68(2):269-280.

68. Alcaín F.J., Burón M.I. (1994). Ascorbate on cell growth and differentiation. Journal of Bioenergetics and Biomembranes. 26(4):393-398.

69. Calvert J.W., Chua W.C., Gharibjanian N.A., Dhar S., Evans G.R.D. (2005). Osteoblastic phenotype expression of MC3T3-E1 cells cultured on polymer surfaces. Plastic and Reconstructive Surgery. 116(2):567-576.

70. Wutticharoenmongkol P., Pavasant P., Supaphol P. (2007). Osteoblastic phenotype expression of MC3T3-E1 cultured on electrospun polycaprolactone fiber mats filled with hydroxyapatite nanoparticles. Biomacromolecules. 8(8):2602-2610.

71. Park J.B. (2012). The effects of dexamethasone, ascorbic acid, and beta-glycerophosphate on osteoblastic differentiation by regulating estrogen receptor and osteopontin expression. J Surg Res. 173(1):99-104. 
Figure 1 - a) Scheme of computer-aided wet-spinning apparatus, b) design of 3D scaffolds with a cylindrical geometry characterized by a $0-90^{\circ}$ lay-down pattern, a diameter of $15 \mathrm{~mm}$ and either 10 or 25 overlapped layers $(\sim 2$ and $5 \mathrm{~mm}$ thickness, respectively) and c) photograph of the produced scaffolds composed by 10 layers (left) and 25 layers (right).

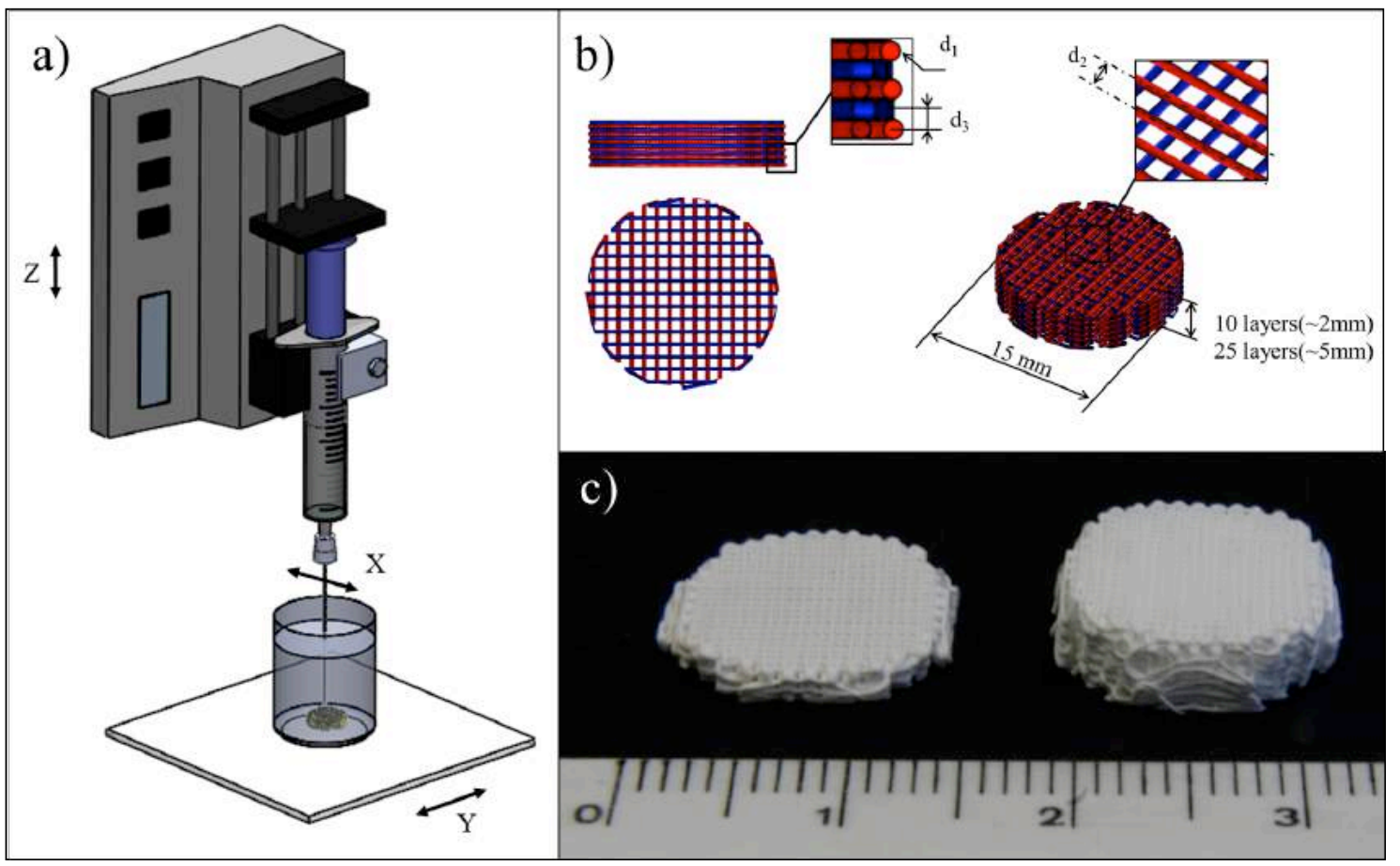


Figure 2 - Backscatter SEM micrographs of the top view and cross-section of *PCL scaffolds obtained for: a) $\mathrm{C}_{*_{\mathrm{PCL}}}$ in the range $20-30 \% \mathrm{w} / \mathrm{v}\left(\mathrm{V}_{\text {dep }}=240 \mathrm{~mm} \cdot \mathrm{min}^{-1}\right.$ and $\left.\left.\mathrm{F}=1 \mathrm{ml} \cdot \mathrm{h}^{-1}\right) ; \mathrm{b}\right) \mathrm{V}_{\text {dep }}$ in the range $200-280 \mathrm{~mm} \cdot \mathrm{min}^{-1}\left(\mathrm{~F}=1 \mathrm{ml} \cdot \mathrm{h}^{-1}\right.$ and $\left.\left.\mathrm{C}_{*_{\mathrm{PCL}}}=30 \% \mathrm{w} / \mathrm{v}\right) ; \mathrm{c}\right) \mathrm{F}$ in the range $0.9-1.1 \mathrm{ml} \cdot \mathrm{h}^{-1}\left(\mathrm{~V}_{\mathrm{dep}}=240 \mathrm{~mm} \cdot \mathrm{min}^{-1}\right.$ and $\left.\mathrm{C}_{*_{\mathrm{PCL}}}=30 \% \mathrm{w} / \mathrm{v}\right)$.
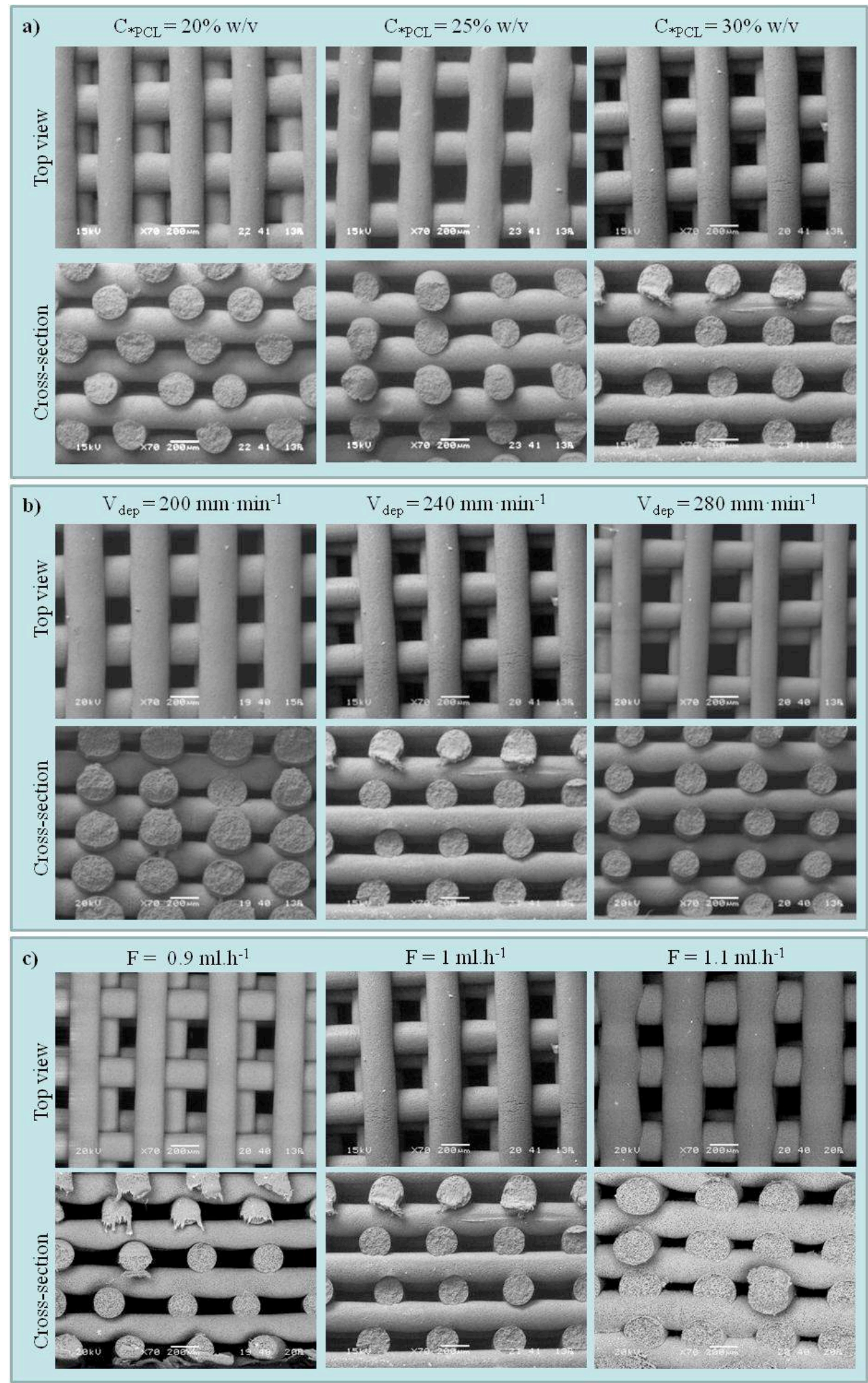
Figure 3 - SEM micrographs showing single fibre porosity: outer surface (a-c) and internal porosity (d-f). Fabrication parameters: $\mathrm{V}_{\text {dep }}=240 \mathrm{~mm} \cdot \mathrm{min}^{-1}, \mathrm{~F}=1 \mathrm{ml} \cdot \mathrm{h}^{-1}$ and $\mathrm{C}_{* \mathrm{PCL}}$ from 20 to $30 \% \mathrm{w} / \mathrm{v}$.
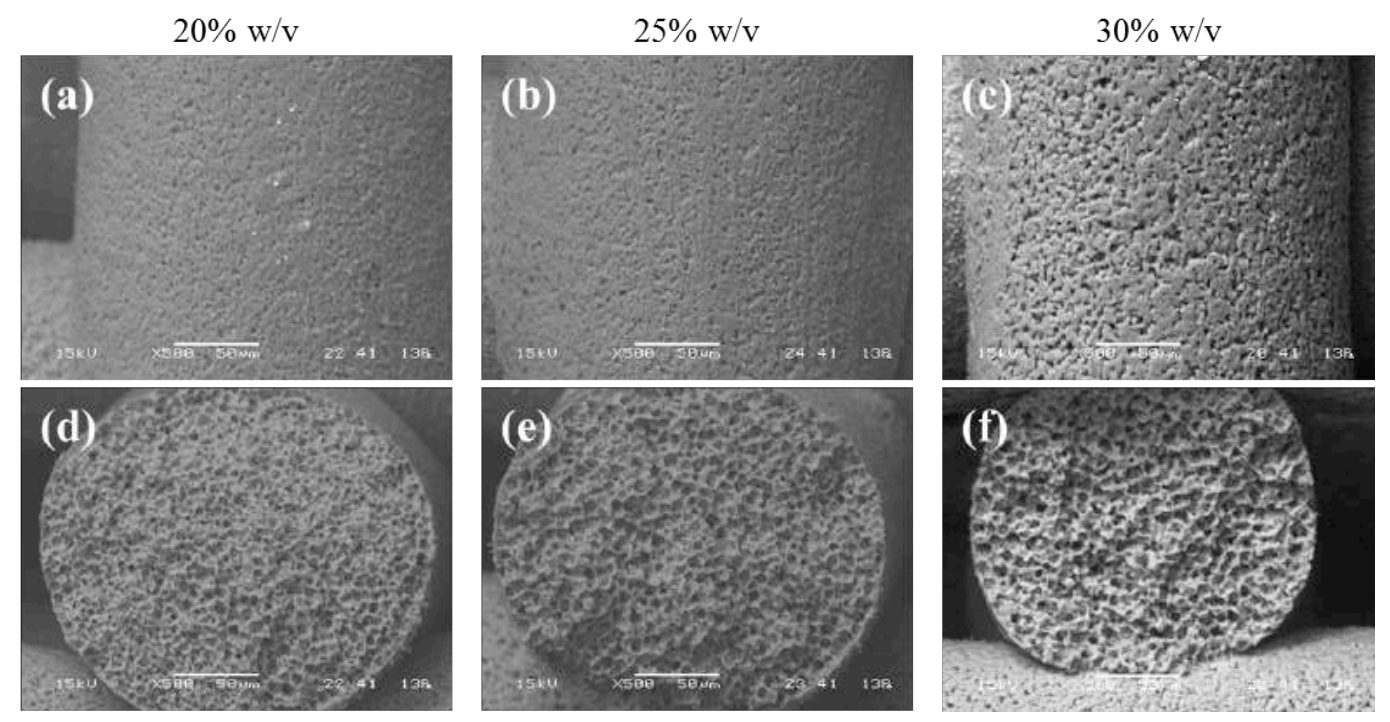

Figure 4 - SEM micrographs of $*$ PCL/HA scaffolds produced with a $\mathrm{C}_{* \mathrm{PCL}}$ of $30 \% \mathrm{w} / \mathrm{v}, \mathrm{F}=1 \mathrm{ml} \cdot \mathrm{h}^{-1}$ and $\mathrm{V}_{\mathrm{dep}}=240 \mathrm{~mm} \cdot \mathrm{min}^{-1}$ : a) top view, b) scaffold cross-section, c) fibre external surface, d) fibre cross-section.
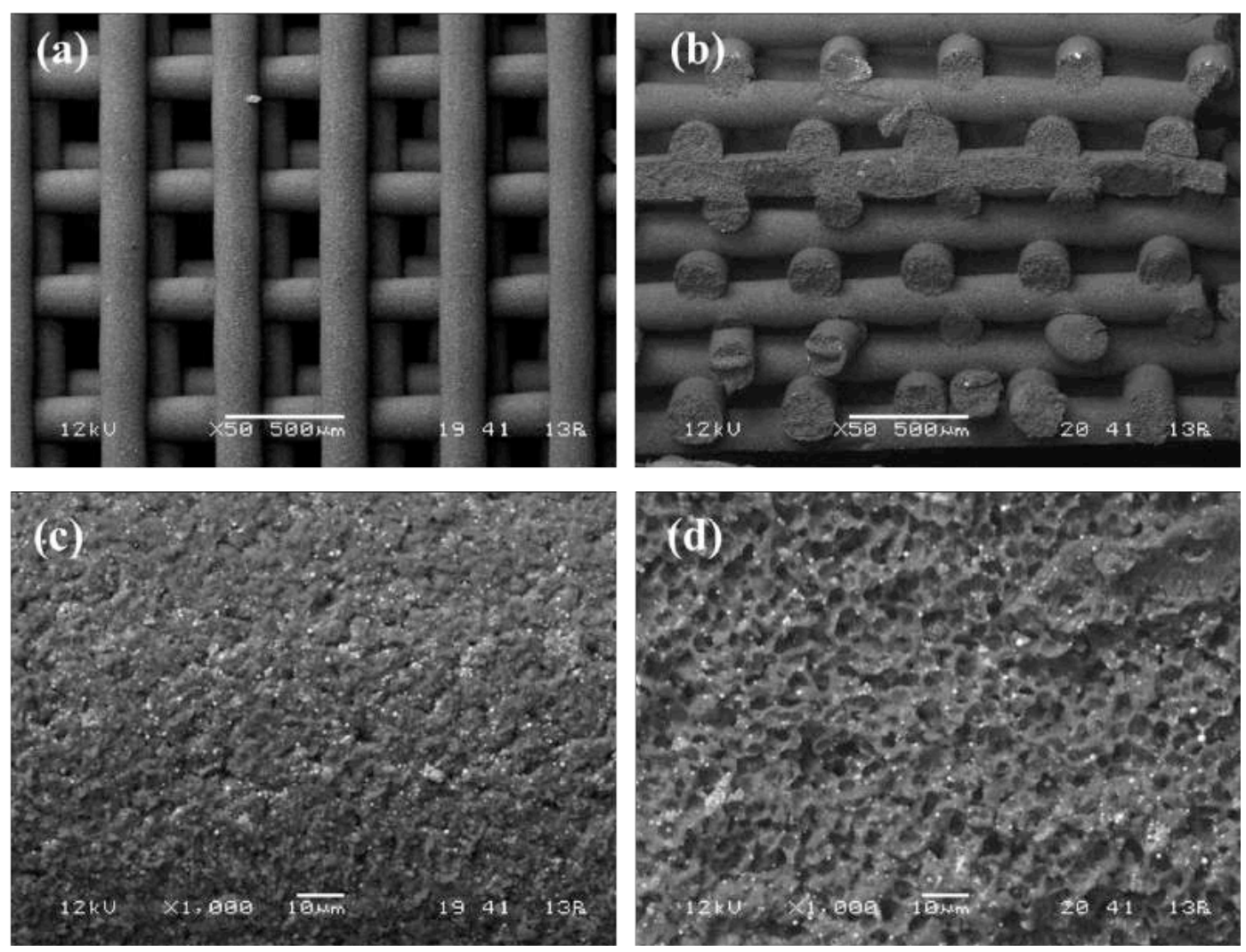
Figure 5 - Typical stress-strain curves obtained for scaffolds produced employing different $\mathrm{C}_{* \mathrm{PCL}}$ and loaded with HA, compressed at a rate of $0.5 \mathrm{~mm} \cdot \mathrm{min}^{-1}$ up to a strain value of $0.5 \mathrm{~mm} \cdot \mathrm{mm}^{-1}$.

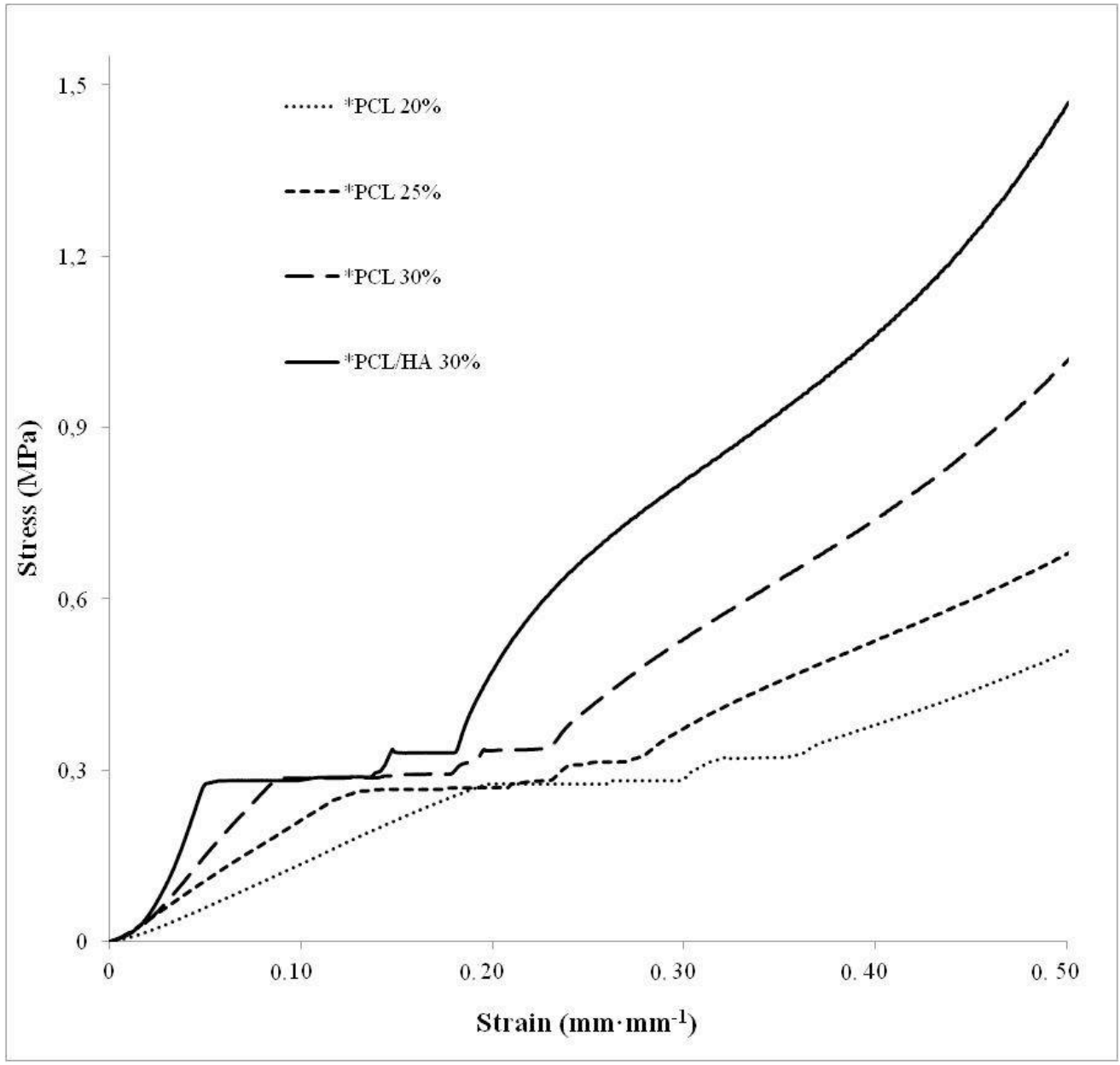


Figure 6 - MC3T3-E1 cell cultured on *PCL and *PCL/HA based scaffolds in non-osteogenic (n.o.) and osteogenic (ost.) medium: a) proliferation investigated by means of WST-1 reagent, b) collagen production investigated by means of Direct Red 80 staining method and c) alkaline phosphatase activity.
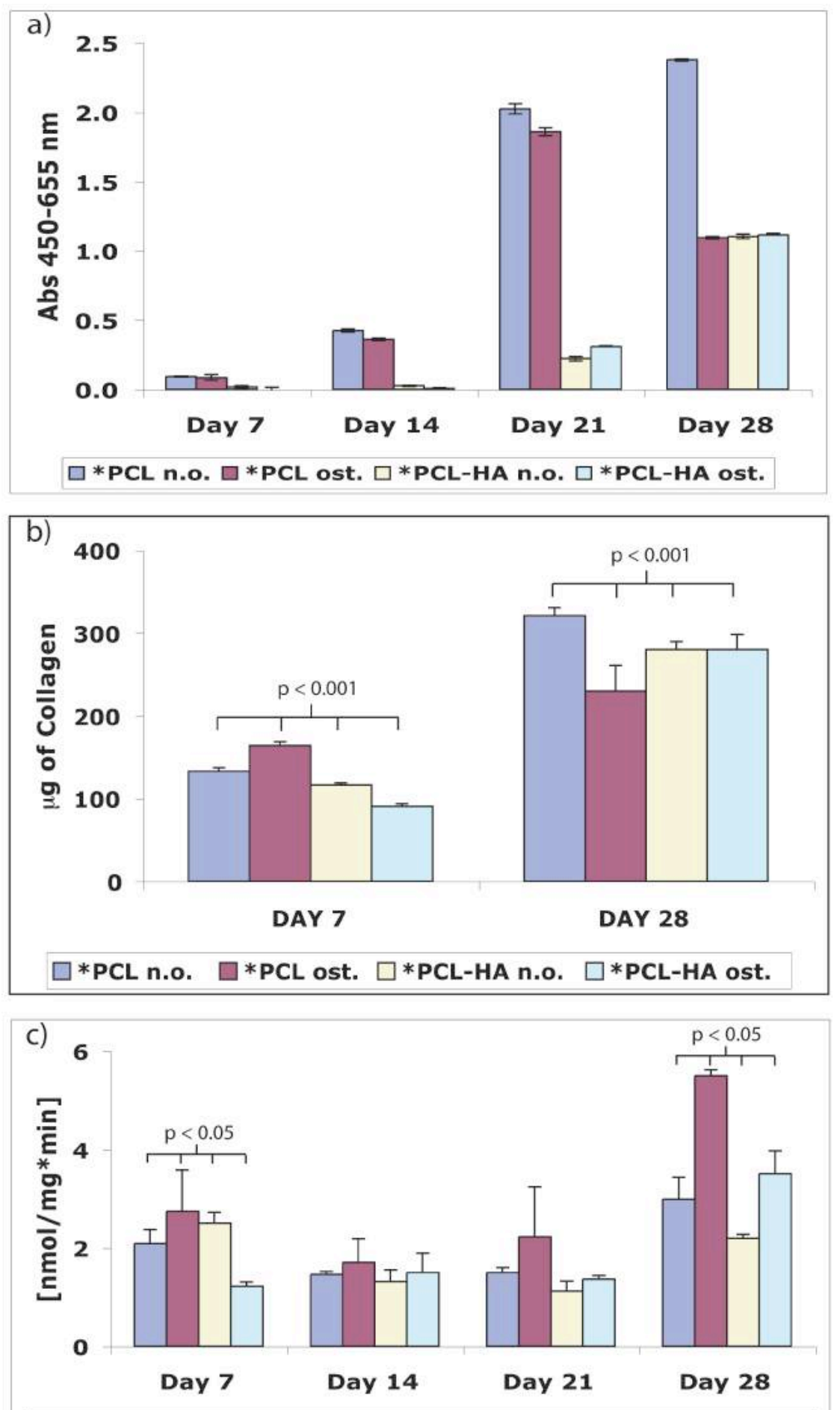

$\square$ *PCL n.o. $\square *$ PCL ost. $\square *$ PCL-HA n.o. $\square *$ PCL-HA ost. 
Figure 7 - CLSM micrograph of MC3T3-E1 cells cultured on *PCL and *PCL/HA scaffolds at different end-points (7, 14, 21 and 28 days) and growing conditions (n.o. = non-osteogenic and ost. = osteogenic) (scale bar=100 $\mu \mathrm{m})$.

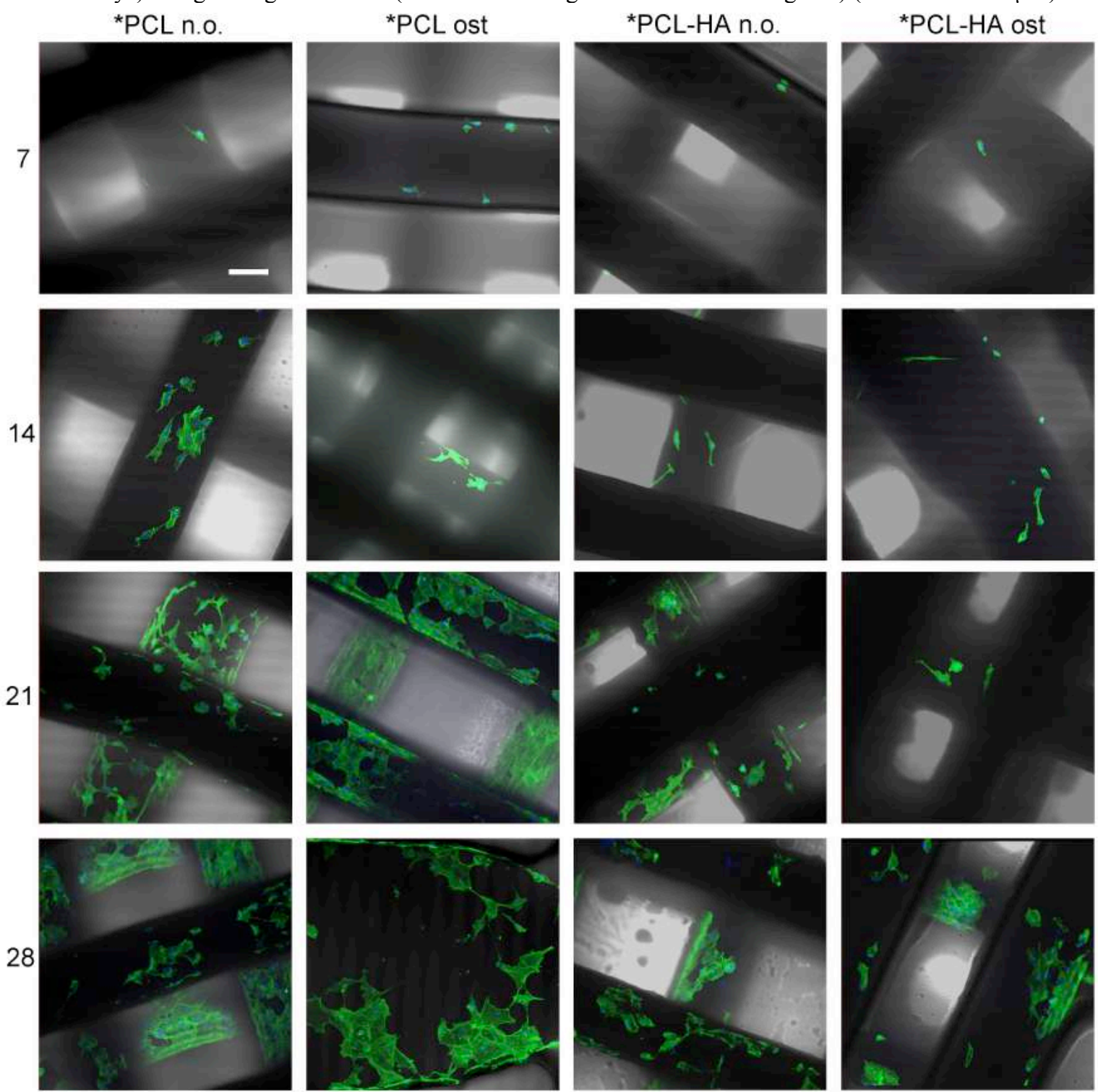


Figure 8 - CLSM micrographs of MC3T3-E1 cells cultured on *PCL (a : non-osteogenic; b:osteogenic) and *PCL/HA (c : non-osteogenic; d:osteogenic) scaffolds at 28 days of culture (scale bar $=50 \mu \mathrm{m})$.
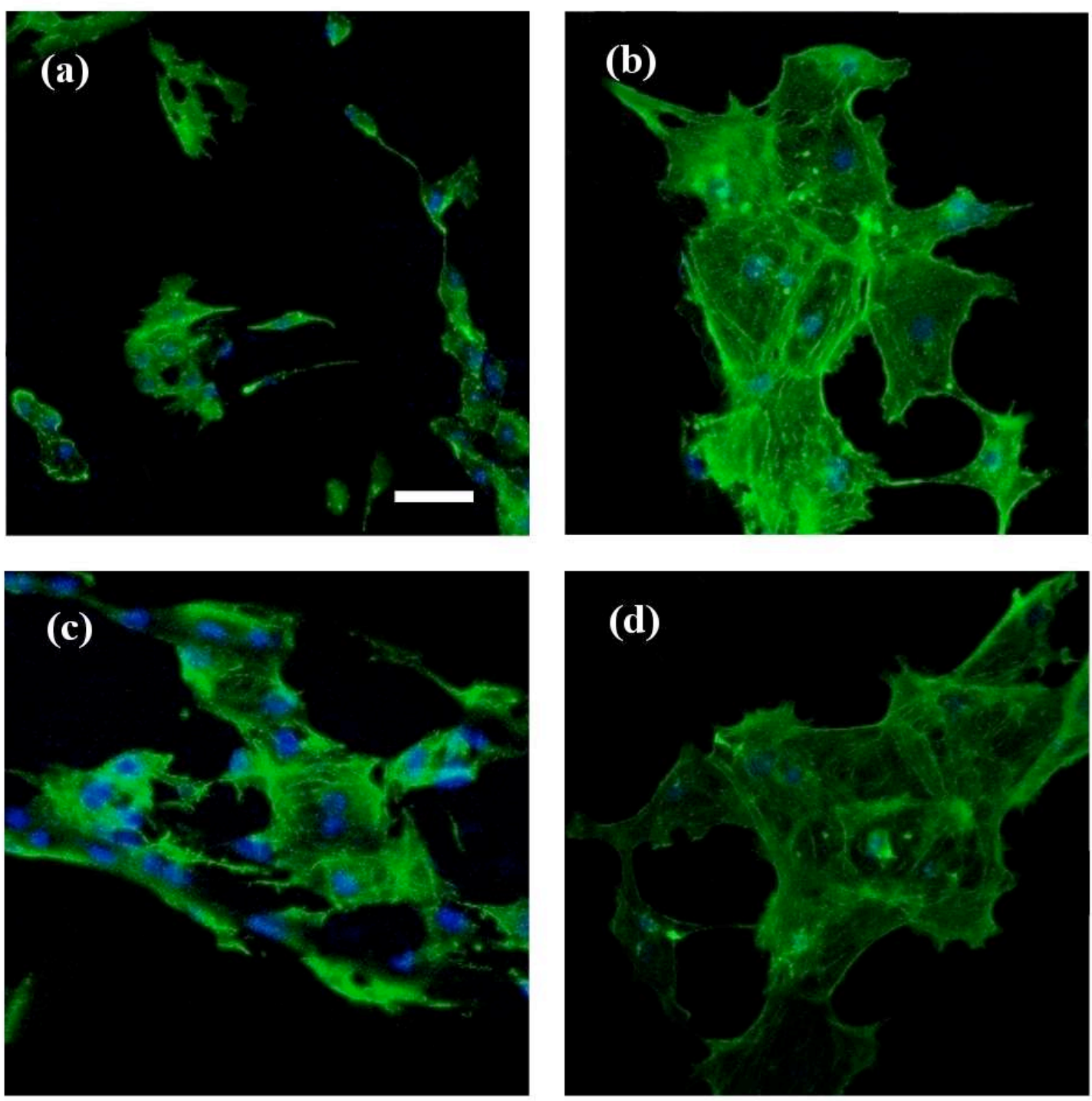
Table 1 - Fibres diameter, pore size and porosity of *PCL and *PCL/HA scaffolds at different processing conditions. Values are presented as mean \pm standard deviation

\begin{tabular}{|c|c|c|c|c|c|}
\hline \multirow{13}{*}{ 己े } & $\begin{array}{c}\text { Polymer } \\
\text { concentration } \\
\left(\mathbf{C}_{* \mathrm{PCL}}\right)[\% \mathrm{w} / \mathrm{v}]\end{array}$ & $\begin{array}{c}\text { Fibre } \\
\text { diameter }\left(d_{1}\right) \\
{[\mu \mathrm{m}]}\end{array}$ & $\begin{array}{c}\text { Pore size } \\
\text { (X and Y axis) } \\
{[\mu \mathrm{m}]}\end{array}$ & $\begin{array}{c}\text { Pore size } \\
\text { (Z axis) } \\
{[\mu \mathrm{m}]}\end{array}$ & $\begin{array}{c}\text { Porosity } \\
{[\%]}\end{array}$ \\
\hline & 20 & $246 \pm 19$ & $225 \pm 40$ & $68 \pm 21^{(*)}$ & 36 \\
\hline & 25 & $242 \pm 18$ & $235 \pm 23$ & $95 \pm 14^{(*)}$ & 43 \\
\hline & 30 & $232 \pm 4$ & $232 \pm 22$ & $126 \pm 12^{(*)}$ & 49 \\
\hline & $\begin{array}{c}\text { Deposition } \\
\text { Velocity }\left(\mathbf{V}_{\mathbf{d e p}}\right) \\
{\left[\mathrm{mm} \cdot \mathrm{min}^{-1}\right]}\end{array}$ & & & & \\
\hline & 200 & $266 \pm 8^{(*)}$ & $190 \pm 19^{(*)}$ & $54 \pm 8^{(*)}$ & 24 \\
\hline & 240 & $232 \pm 4^{(*)}$ & $232 \pm 22^{(*)}$ & $126 \pm 12$ & 49 \\
\hline & 280 & $201 \pm 8^{(*)}$ & $279 \pm 40^{(*)}$ & $118 \pm 15$ & 59 \\
\hline & $\begin{array}{c}\text { Feed Rate (F) } \\
{\left[\mathrm{ml} \cdot \mathrm{h}^{-1}\right]}\end{array}$ & & & & \\
\hline & 0.8 & $189 \pm 4^{(*)}$ & $\begin{array}{c}256 \pm 33 \\
(* \mathrm{vs} .1 .0 \text { and } 1.1 \mathrm{ml} \cdot \mathrm{h}-1)\end{array}$ & $\begin{array}{c}122 \pm 9 \\
(* \text { vs. } 0.9 \text { and } 1.11 \mathrm{ml} \cdot \mathrm{h}-1)\end{array}$ & 60 \\
\hline & 0.9 & $195 \pm 3^{(*)}$ & $\begin{array}{c}271 \pm 31 \\
(* \mathrm{vs} .1 .0 \text { and } 1.11 \mathrm{ml} \cdot \mathrm{h}-1)\end{array}$ & $109 \pm 9^{(*)}$ & 58 \\
\hline & 1.0 & $232 \pm 4^{(*)}$ & $232 \pm 22^{(*)}$ & $\begin{array}{c}126 \pm 12 \\
(* \text { vs. } 0.9 \text { and } 1.11 \mathrm{ml} \cdot \mathrm{h}-1)\end{array}$ & 49 \\
\hline & 1.1 & $274 \pm 8^{(*)}$ & $297 \pm 38^{(*)}$ & $62 \pm 12^{(*)}$ & 26 \\
\hline \multirow{3}{*}{$\underbrace{\}_{*}$} & $\begin{array}{c}\text { Polymer } \\
\text { concentration } \\
(\mathbf{C} * \text { PCL })[\% \mathrm{w} / \mathrm{v}]\end{array}$ & \multicolumn{4}{|c|}{$V_{d e p}=240 \mathrm{~mm} \cdot \min ^{-1} ; F=1 \mathrm{ml} \cdot \mathrm{h}^{-1}$} \\
\hline & 20 & $194 \pm 6^{(* * *)}$ & $280 \pm 23^{(* *)}$ & $99 \pm 8^{(* *)}$ & 58 \\
\hline & 30 & $202 \pm 2^{(*, * *)}$ & $275 \pm 25^{(* *)}$ & $89 \pm 17^{(* *)}$ & 54 \\
\hline
\end{tabular}

$\left.{ }^{*}\right)$ parameter significantly different $(p<0.05)$ when compared to those of other scaffolds developed within each independent study of processing variable effect $\left(\mathrm{C}_{* \mathrm{PCL}}, \mathrm{V}_{\mathrm{dep}}\right.$ and $\left.\mathrm{F}\right),(* *)$ parameter significantly different $(\mathrm{p}<0.05)$ when compared to that of the analogous plain *PCL scaffold obtained applying the same processing conditions.

Table 2 - Compressive modulus and maximum stress of scaffolds produced with different $\mathrm{C} * \mathrm{PCL}$ and loaded with HA. The obtained values are reported as mean \pm standard deviation $(n=5)$.

\begin{tabular}{|c|c|c|c|}
\hline \multirow{2}{*}{ Scaffold } & $\begin{array}{c}\mathbf{C}_{* \text { *PCL }} \\
{[\% \mathrm{w} / \mathrm{v}]}\end{array}$ & $\begin{array}{c}\text { Compressive Modulus } \\
{[\mathrm{MPa}]}\end{array}$ & $\begin{array}{c}\text { Maximum Stress } \\
\mathbf{5 0 \%} \text { strain) } \\
{[\mathrm{MPa}]}\end{array}$ \\
\hline \multirow{2}{*}{$*$ PCL } & 20 & $1.42 \pm 0.44^{(*)}$ & $0.54 \pm 0.08^{(* \text { vs } 30 \%)}$ \\
\cline { 2 - 4 } & 25 & $2.78 \pm 0.70^{(* \text { vs } 20 \%)}$ & $0.65 \pm 0.09^{(* \text { vs } 30 \%)}$ \\
\cline { 2 - 4 } & 30 & $3.62 \pm 0.94^{(* \text { vs } 20 \%)}$ & $0.96 \pm 0.11^{(*)}$ \\
\hline *PCL/HA & 30 & $7.28 \pm 1.26^{(* *)}$ & $1.51 \pm 0.26^{(* *)}$ \\
\hline
\end{tabular}

(*) parameter significantly different $(\mathrm{p}<0.05)$ when compared to those of other scaffolds with different $\mathrm{C}_{* \mathrm{PCL}},(* *)$ parameter significantly different $(\mathrm{p}<0.05)$ when compared to that of the analogous plain *PCL scaffold obtained employing the same $\mathrm{C}_{* \mathrm{PCL}}(30 \% \mathrm{w} / \mathrm{v})$. 
Table 3 - Thermal properties of raw *PCL and *PCL-based scaffolds obtained by means of TGA and DSC.

\begin{tabular}{|l|c|ccc|ccc|}
\hline & & \multicolumn{3}{|c|}{$\mathbf{1}^{\text {st }}$ heating } & \multicolumn{3}{c|}{$\mathbf{2}^{\text {nd }}$ heating } \\
& $\begin{array}{c}\mathbf{T}_{\mathbf{d}} \\
\left({ }^{\circ} \mathbf{C}\right)\end{array}$ & $\begin{array}{c}\mathbf{T}_{\mathbf{g}} \\
\left({ }^{\circ} \mathbf{C}\right)\end{array}$ & $\begin{array}{c}\mathbf{T}_{\mathbf{m}} \\
\left({ }^{\circ} \mathbf{C}\right)\end{array}$ & $\mathbf{C} \%$ & $\begin{array}{c}\mathbf{T}_{\mathbf{g}} \\
\left({ }^{\circ} \mathbf{C}\right)\end{array}$ & $\begin{array}{c}\mathbf{T}_{\mathbf{m}} \\
\left({ }^{\circ} \mathbf{C}\right)\end{array}$ & $\mathbf{C} \%$ \\
\hline *PCL raw & 311.05 & -63.70 & 66.91 & 61.95 & -64.37 & 56.08 & 51.41 \\
*PCL scaffold & 317.75 & -62.01 & 62.60 & 67.40 & -63.52 & 56.33 & 51.85 \\
*PCL/HA scaffold & 310.66 & -60.86 & 63.28 & 66.82 & -64.19 & 56.62 & 53.41 \\
\hline
\end{tabular}

